\title{
Assessing SWMM 5 Hydrologic Parameter Benefits for Model \\ Calibration
}

\author{
Justin Siegrist, ${ }^{1}$ Daniel Anderson, ${ }^{2}$ Joseph Koran, ${ }^{2}$ Mark Pribak, ${ }^{3}$ Uzair M. (Sam) Shamsi ${ }^{4}$ and Dave \\ White ${ }^{1}$ \\ ${ }^{1}$ Wade Trim, Inc., Cincinnati, Ohio; ${ }^{2}$ Metropolitan Sewer District of Greater Cincinnati, Cincinnati, Ohio; ${ }^{3}$ Wade Trim, Inc., Detroit,
} Michigan; ${ }^{4}$ Jacobs, Pittsburgh, Pennsylvania.

\begin{abstract}
A 33 acre (13.2 ha) sewershed in Cincinnati, Ohio that is regulated by sanitary sewer overflow (SSO) structure 228 experiences high amounts of rain derived inflow and infiltration (RDII), which leads to overflows. The amount of overflow that SSO 228 discharges during a typical rainfall year must be significantly reduced per a federal consent decree between the United States Environmental Protection Agency (USEPA) and the Metropolitan Sewer District of Greater Cincinnati (MSDGC). As part of the SSO reduction alternatives development and planning process, a system wide model (SWM) representation of the SSO 228 sewershed system was developed and subsequently calibrated and validated in 2012 within the USEPA Storm Water Management Model, Version 5 (SWMM5) model framework.
\end{abstract}

As the SSO 228 overflow reduction preferred alternative development progressed from planning to detailed design, the SSO 228 SWM received additional refinement, as well as recalibration and validation. As a part of the model refinement effort, the SSO 228 SWM was evaluated as a pilot study to test additional modeling techniques available in the SWMM5 program that may be useful in other areas of the MSDGC system. These additional techniques included the use of initial abstraction and drying time, seasonally varied RDII parameters, and application of the Aquifer module to simulate groundwater impacts.

Results and conclusions drawn from this pilot study were used to reevaluate the MSDGC approach to calibration and validation, assess the benefit of the additional hydrologic parameters, and develop guidelines for determining model complexity based on monitored flow data trends.

\section{Introduction}

The sanitary sewer overflow (SSO) 228 tributary area depicted in Figure 1 overleaf is a 33 acre (13.4 ha) sanitary sewer system within the Upper Duck Creek watershed in Cincinnati, Ohio.

The SSO 228 system experiences significant amounts of rain derived inflow and infiltration (RDII), which causes frequent overflows during wet weather. The SSO 228 regulator structure controls both overflows to a stormwater pipe that discharges directly to surface waters, and flows to the downstream sewer system. During wet weather, flow from the SSO 228 basin exceeds the capacity of the downstream sewer, causing an SSO.

The Final Wet Weather Improvement Program (WWIP) (Metropolitan Sewer District of Greater Cincinnati 2010) requires that SSO 228 overflows be eliminated for storms up to, and including the 2 y Soil Conservation Service (SCS) Type II distribution design storm event. To achieve this, SSO control alternatives were evaluated as part of the Upper Duck All Bundle (UDAB) project (Wade Trim 2013). Development of this alternative required the use of a calibrated System Wide Model (SWM) representation of the SSO 228 area, which is included in the UDAB SWM (Wade Trim 2012). This paper documents the most current model calibrationvalidation effort performed for the SSO 228 area.

\section{Background}

The 2012 UDAB SWM calibration effort was concluded in February of 2012, and is documented in the Task 207 Revised Model Validation dated February 28, 2012 (Wade Trim 2012). The 2012 SWM representation of the SSO 228 area is shown in Figure 2 overleaf.

At the time of the 2012 UDAB calibration, the MSDGC Modeling Guidelines and Standards: Volume I System Wide Model (Modeling Standards, XCG Consultants 2012) had not yet been finalized. Despite this, the model was calibrated to a level deemed acceptable by MSDGC.

Siegrist, J., D. Anderson, J. Koran, M. Pribak, U. M. Shamsi and D. White. 2016. Assessing SWMM 5 Hydrologic Parameter Benefits for Model Calibration. Journal of Water Management Modeling 25:C406. doi:10.14796/JWMM.C406 @ CHI 2016. www.chijournal.org ISSN 2292-6062. 


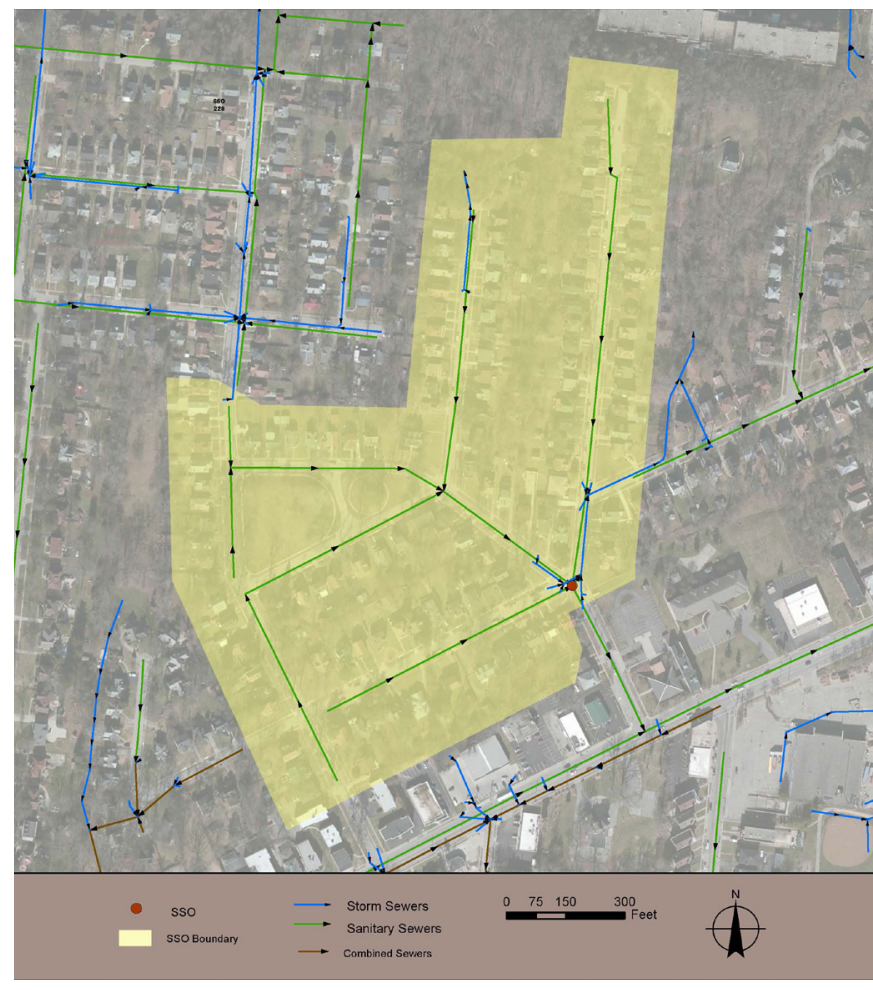

Figure 1 SSO 228 overview.

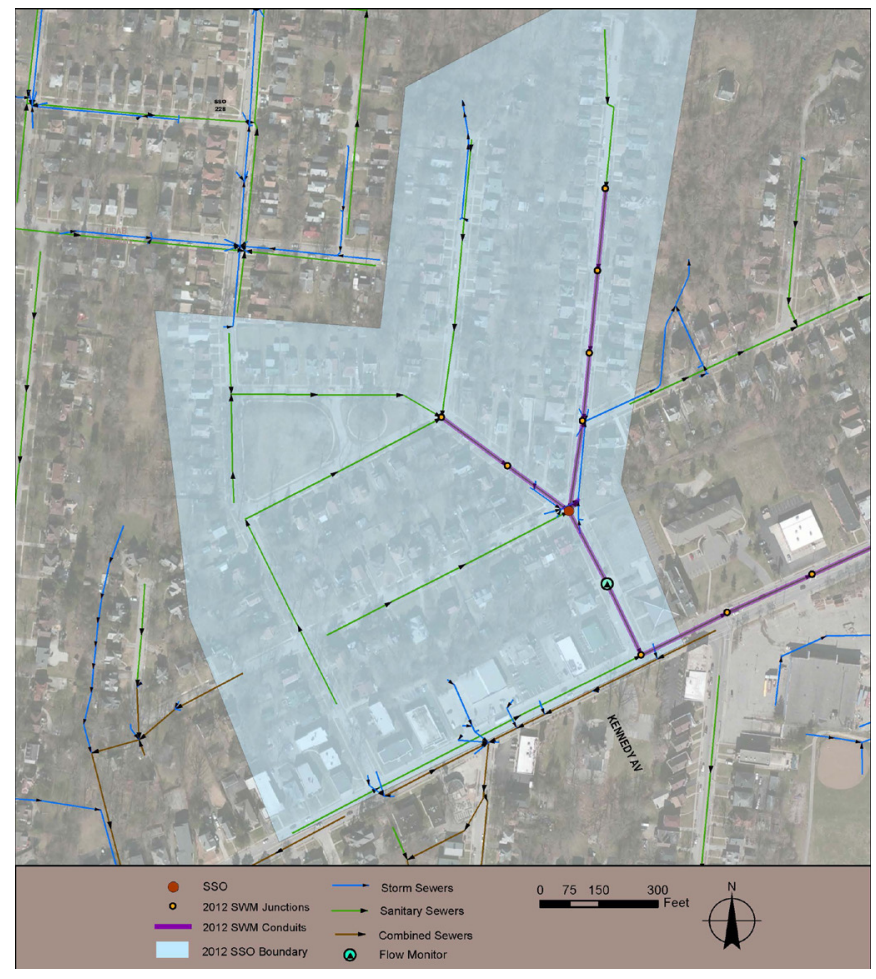

Figure 2012 SSO 228 SWM representation.

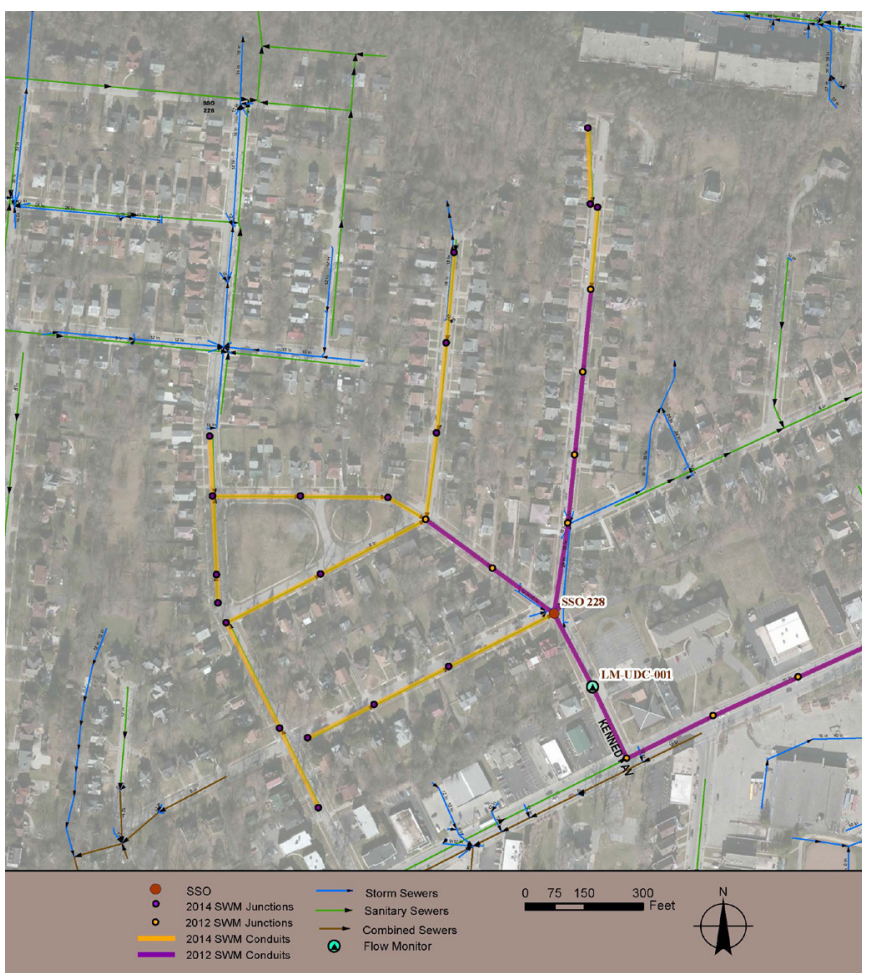

Figure 32014 hydraulic updates to the SSO 228 SWM representation.

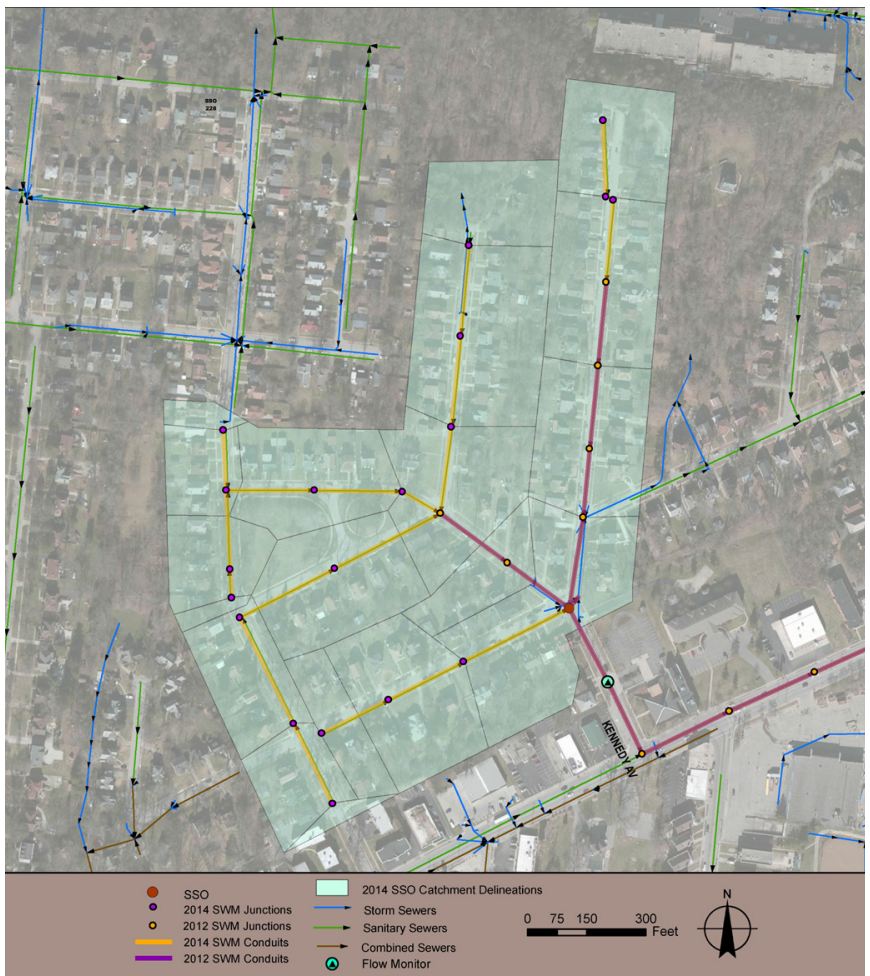

Figure 42014 refined tributary sewershed delineation.

Siegrist, J., D. Anderson, J. Koran, M. Pribak, U. M. Shamsi and D. White. 2016. Assessing SWMM 5 Hydrologic Parameter Benefits for Model Calibration. Journal of Water Management Modeling 25:C406. doi:10.14796/JWMM.C406 @ CHI 2016. www.chijournal.org ISSN 2292-6062. 
Since the 2012 UDAB calibration was completed, MSDGC released a third revision of the modeling standards dated February 2013 (XCG Consultants 2013). To confirm that the model was acceptable for use in detailed design, MSDGC directed Wade Trim (WT) to conduct an additional calibration effort for the SSO 228 basin, which was intended to refine the SWM's performance and validate the SWM to meet revision 3 of the MSDGC modeling standards (XCG Consultants 2013).

As a part of the model refinement effort, the SSO 228 area was evaluated as a pilot study to test additional modeling techniques available in the USEPA SWMM5 program — which is what the SWM's framework consists of - that may be useful in other areas of the MSDGC system. These additional techniques included the use of initial abstraction, drying time, seasonal variation in the RTK parameters (further explanation is provided in Section 6), and application of the Aquifer module to simulate groundwater impacts.

Results and conclusions drawn from this pilot study were used to reevaluate the MSDGC approach to calibration-validation, which, if adopted, could be applied to the remainder of the UDAB SWM.

\section{MSDGC Calibration and Validation Require- ments}

The current MSDGC modeling standards, revision 3, published in February, 2013 (XCG Consultants 2013) specifies the following model accuracy tolerances.

\section{Dry Weather Flow}

MSDGC modeling standards specify the following tolerances for dry weather flow (DWF) comparisons.

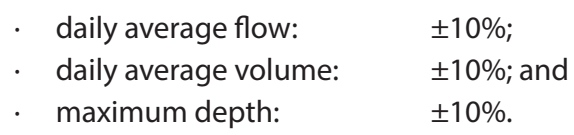

\section{Wet Weather Flow}

MSDGC modeling standards revision 3 specifies the following model accuracy tolerances for peak flow, total event volume and peak depth in addition to overall flow hydrograph shape when comparing modeled results to observed data for wet weather events.

$$
\begin{aligned}
& \text { peak flow: } \quad+25 \% /-15 \% \text {; } \\
& \text { total event volume: } \quad+20 \% /-10 \% \text {; and } \\
& \text { peak depth: } \quad \pm 15 \% \text { or model accu- }
\end{aligned}
$$

racy can be verified by comparing scatter plots to demonstrate similar behavior between modeled and observed depth and flow.

Based on discussions with MSDGC, the Wastewater Planning Users Group (WaPUG) Code of Practice for the Hydraulic Modelling of Sewer Systems (WaPUG Modeling Standards, Wastewater Planning Users Group 2002) could also be used for comparison of peak depth. This is due in part to the variability in the depth of flow when a pipe becomes surcharged, which the WaPUG modeling standards address explicitly. This is also due to the fact that in a small pipe, such as the one that was monitored for this calibration effort, relative minor absolute differences between modeled and measured depth will have large percentage differences that do not provide an accurate assessment of the SWM's ability to simulate flow depth.

The WaPUG standards for peak depth comparison are:

- surcharged conditions: $+1.6 \mathrm{ft}$ to $-0.3 \mathrm{ft}(0.5 \mathrm{~m}$ to $-0.1 \mathrm{~m}) ;$ and

- unsurcharged conditions: $\pm 0.33 \mathrm{ft}(0.1 \mathrm{~m})$.

Based upon discussions with MSDGC, it was determined that for acceptance as meeting the standards, the following must occur:

- for an event to be considered successful, it must meet the criteria for peak flow, total event volume and peak depth;

- a minimum of $67 \%$ of the calibration events must meet the numerical criteria for peak flow, total event volume and peak depth; and

- a minimum of $67 \%$ of validation events must meet the numerical criteria for peak flow, total event volume and peak depth.

\section{Updates}

\subsection{Hydraulic Updates}

The SWM representation of the SSO 228 sewer system was updated to include all the upstream pipes in the system. Using 2012 Cincinnati Area Geographical Information System (CAGIS) data (City of Cincinnati 2012), the remainder of the upstream sewer system was added to the SSO 228 SWM representation, as depicted in Figure 3 above.

This model expansion included the addition of eighteen 8 in. $(0.2 \mathrm{~m})$. conduits and eighteen nodes to the SWM. The model was expanded to better assess hydraulic grade lines in the upstream collection system.

\subsection{Hydrologic Updates}

The tributary sewershed area was redelineated and redistributed to provide a more refined representation of the overall system. A more detailed delineation of subareas within a collection system is useful in obtaining a more representative distribution of dry and wet weather flow in each pipe. For the 2014 revised SSO 228 model, the original delineation used for the 2012 UDAB calibration was divided into smaller subareas, and the inflows were distributed throughout the sewer system.

The 2012 representation shown in Figure 2 above contained 43 acres (17.4 ha) of tributary sewershed area that was distributed to three inflow nodes. The refined delineation resulted in 33 acres (13.4 ha) of tributary sewershed area distributed to 19 inflow nodes. See Figure 4 above for a depiction of the refined tributary sewershed delineation. 
Definitions of subareas were adjusted to follow parcel boundaries for homes with lateral connections to the SSO 228 sewer lines, consistent with MSDGC practice. Definitions of subareas are somewhat subjective when applied to the sanitary system within this particular sewershed, as detailed field investigations and documentation of direct surface area inflow connections were not available. Instead, the overall effects of inflow and infiltration are being approximated by RTK parameters (see Section 6).

\section{Observed Data Refinements}

To provide for a direct comparison to the previous work, observed data used in the 2012 calibration-validation effort were used for the 2014 calibration-validation effort. A review of the data revealed several data gaps in the rainfall record that were expected to influence the Aquifer module parameters. Refinements to the rainfall data are presented below.

\section{Rainfall Data}

Rainfall data from radar rainfall basin LM-DC-025 were used as the rainfall inputs for the 2014 calibration with a few changes. The original radar rainfall data were processed on an event basis, where events are defined when $50 \%$ of all working gauges have an accumulation of $0.05 \mathrm{in}$. (1.3 mm) for any given hour (Vieux, Inc. 2011). As a result, there is missing rainfall data in the radar rainfall record for several storm events. Figure 5 depicts an example of this occurrence.

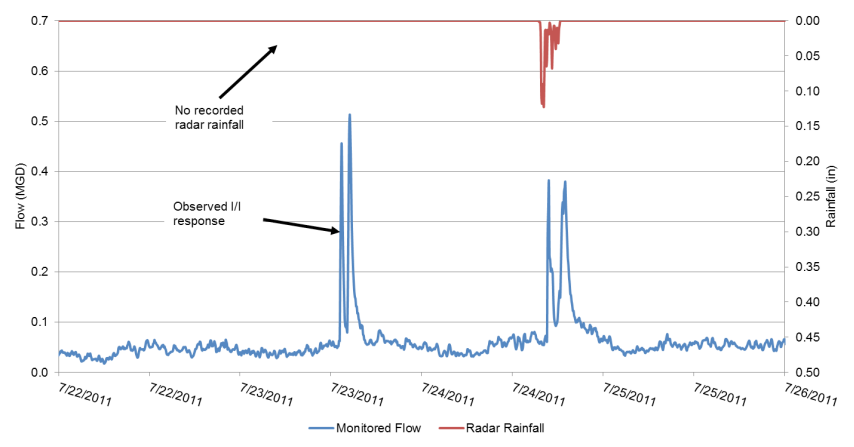

Figure 5 Example of radar rainfall data gaps at SSO 228.

One of the goals of the 2014 calibration was to implement upgrades that accounted for antecedent moisture conditions. Periods of missing rainfall would prevent the model from fully representing the wetting and drying of the soil moisture content and corresponding groundwater level in the aquifer representation. To supplement the data, rainfall data collected at MSDGC's nearby Ross Moyne Deer Park rain gauge located at Matson and Blue Ash Road were used to supplement the radar rainfall data with the missing events. Figure 6 shows the locations of the radar rainfall basin and rain gauge relative to the SSO 228 area.

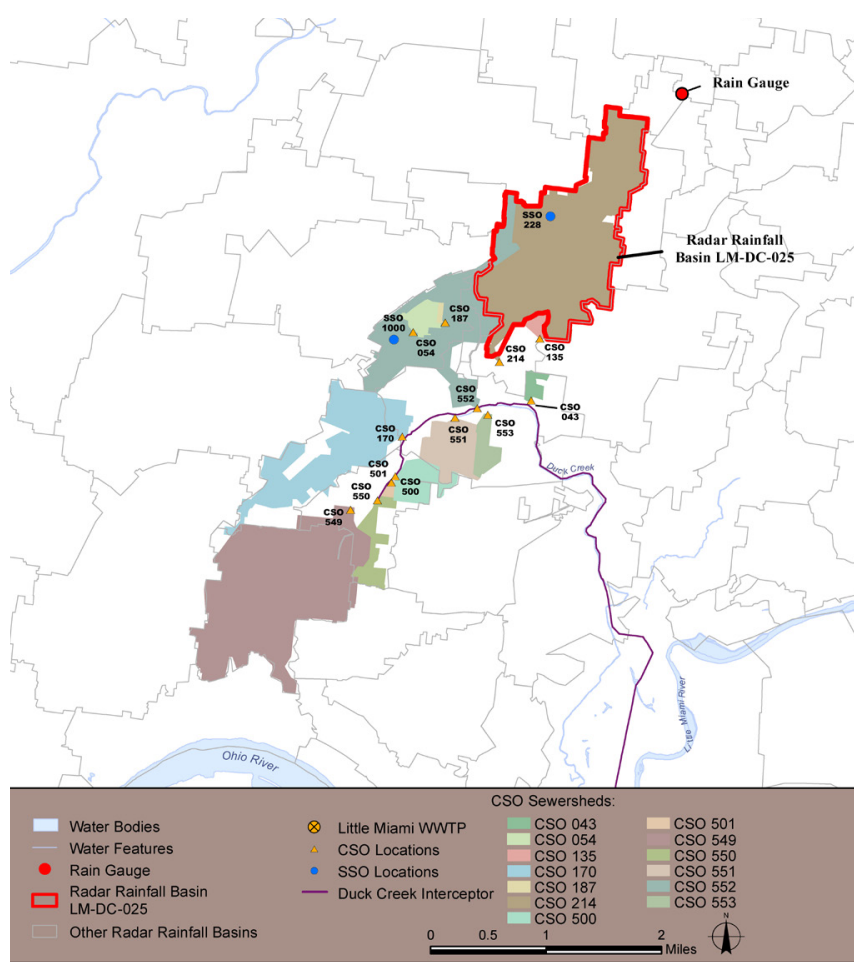

Figure 6 Radar rainfall basin and rain gauge location.

Figure 7 shows an example radar rainfall data gap that has been supplemented with rain gauge data.

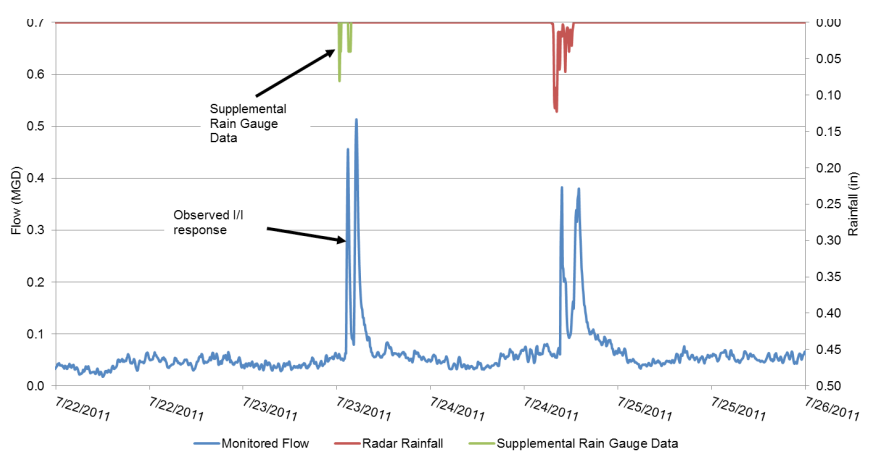

Figure 7 Example of use of supplemental rain gauge data.

Supplemental rain gauge data were implemented every time a wet weather flow response occurred without any recorded radar rainfall data. Table 1 provides a list of storm events that were supplemented by the Ross Moyne Deer Park rain gauge data.

Table 1 Storm events added to the rainfall record input.

\begin{tabular}{lcccc}
\hline \multirow{2}{*}{ Storm Event } & Start of Supplemental & \multicolumn{2}{c}{ End of Supplemental } & \multicolumn{2}{c}{ Total Elapsed } & Total Rainfall Volume \\
& Rain Gauge Data & Rain Gauge Data & Time $(\mathrm{h})$ & for Event (in.) \\
\hline $4 / 9 / 2011^{(1)}$ & $4 / 9 / 201111: 55$ & $4 / 9 / 201115: 45$ & 3.8 & $0.6(5.2 \mathrm{~mm})$ \\
$4 / 16 / 2011^{(1)}$ & $4 / 15 / 201102: 45$ & $4 / 16 / 201104: 00$ & 5.3 & $1.0(25.4 \mathrm{~mm})$ \\
$6 / 18 / 2011$ & $6 / 18 / 201109: 45$ & $6 / 18 / 201109: 55$ & 0.2 & $0.04(1.0 \mathrm{~mm})$ \\
$7 / 4 / 2011$ & $7 / 4 / 201109: 05$ & $7 / 4 / 201109: 25$ & 0.3 & $0.2(5.1 \mathrm{~mm})$ \\
$7 / 23 / 2011$ & $7 / 23 / 201112: 15$ & $7 / 23 / 201113: 50$ & 1.6 & $0.32(8.1 \mathrm{~mm})$ \\
$8 / 14 / 2011$ & $8 / 14 / 201119: 25$ & $8 / 14 / 201119: 50$ & 0.4 & $0.12(3.0 \mathrm{~mm})$ \\
\hline
\end{tabular}

(1) Radar rainfall data for this event were omitted because of recorded timing issues 
With the rainfall data set complete, the rainfall input was ready for use in a continuous model simulation. For event comparisons, the same storm events that were used for the 2012 calibration-validation effort were also used for the 2014 calibration-validation. Table 2 lists the storm events and whether they were used for calibration or validation.

Table 2 Storm events added to the rainfall record input.

\begin{tabular}{lcccccccc}
\hline $\begin{array}{c}\text { 2011 Storm } \\
\text { Period }\end{array}$ & Use ${ }^{(1)}$ & \multicolumn{4}{c}{ Maximum Depth (in.) } & \multicolumn{4}{c}{ Recurrence Interval $^{(2)}$} \\
& $1 \mathrm{~h}$ & $6 \mathrm{~h}$ & $24 \mathrm{~h}$ & Total & $1 \mathrm{~h}$ & $6 \mathrm{~h}$ & $24 \mathrm{~h}$ \\
\hline April 4-6 & $\mathrm{C}$ & 0.56 & 0.99 & 0.99 & 0.99 & - & 2 month & - \\
April 11-15 & $\mathrm{C}$ & 0.33 & 0.85 & 1.98 & 1.98 & - & - & 6 month \\
April 19-22 & $\mathrm{V}$ & 0.67 & 1.49 & 2.69 & 3.39 & 2 month & 6 month & 1 year \\
April 22-30 & $\mathrm{V}$ & 0.66 & 0.86 & 2.34 & 3.26 & 2 month & - & 1 year \\
May 25-27 & $\mathrm{C}$ & 0.32 & 0.52 & 0.90 & 0.90 & - & - & - \\
June 10-12 & $\mathrm{C}$ & 0.63 & 0.89 & 2.03 & 2.07 & 2 month & - & 6 month \\
July 8-9 & $\mathrm{V}$ & 0.36 & 1.04 & 1.04 & 1.04 & - & 2 month & - \\
August 8-9 & $\mathrm{V}$ & 0.73 & 1.05 & 1.11 & 1.05 & 3 month & 3 month & - \\
\hline (1) C: calibration storm; V: validation storm. & (2) - indicates recurrence interval <2 month.
\end{tabular}

\section{Observed Flow Data}

Observed flow data provided by MSDGC from monitor LMUDC-001 were used for shape, peak flow, total event volume and peak depth comparisons. The LM-UDC-001 monitor was installed in manhole number 45116029 and monitored flow from pipe $45116030-45116029$, which is the 8 in. $(0.2 \mathrm{~m})$ underflow pipe from the SSO 228 regulator. Figure 8 shows the location of the LM-UDC-001 flow monitor.

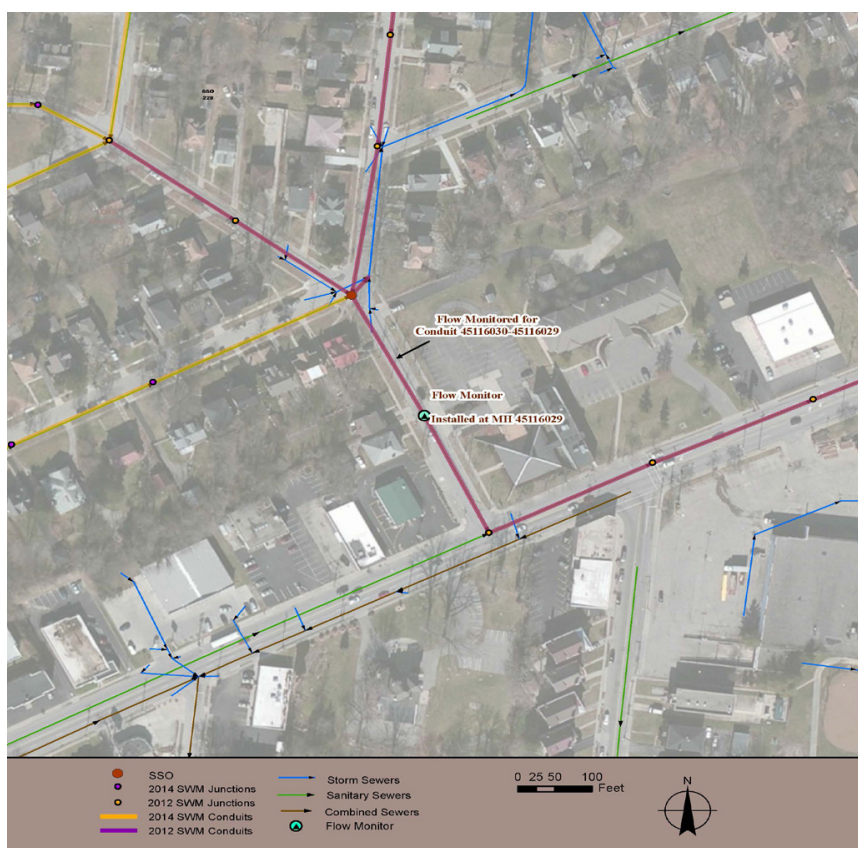

Figure 8 Location of SSO 228 flow monitor.

Flow monitoring data were used as is, and efforts to modify the data or substitute corrected values based on the use of a rating curve were not performed and considered beyond the scope of work. This flow monitor generally performed properly, but did have periods in which the velocity data were missing. Periods with suspect flow data were eliminated from both model and observed flow when calculating percent difference comparisons.

\section{Calibration Refinement}

Data from the LM-UDC-001 monitor were used to adjust the model parameters to calibrate the SWM. The rainfall data set as discussed in Section 5 was used as rainfall inputs. The modeled flows were developed over a continuous period from 2011-03-01 to 2011-10-01. Adjustments for calibration were based on the results of the selected calibration storms in April, May and August. The model results were compared to measured data for peak flow, total event volume, peak flow depth, and the shape of the flow hydrograph.

\section{Dry Weather Flow}

The DWF pattern was modified to be representative of the lowest baseflow observed during the monitoring period, which was in August. This was assumed to represent true dry weather flow independent of rainfall and groundwater effects. Using the USEPA Sanitary Sewer Overflow Analysis and Planning (SSOAP) Toolbox software, the monitored flow hydrograph was decomposed during dry periods in August, and a diurnal pattern was developed and distributed to each inflow node along with a proportional dry weather flow contribution. Further calibration and refinement was done in order to meet MSDGC modeling standards (XCG Consultants 2013). Figure 9 shows a comparison of the 2014 calibrated DWF pattern to the observed DWF pattern, as well as the 2012 DWF pattern.

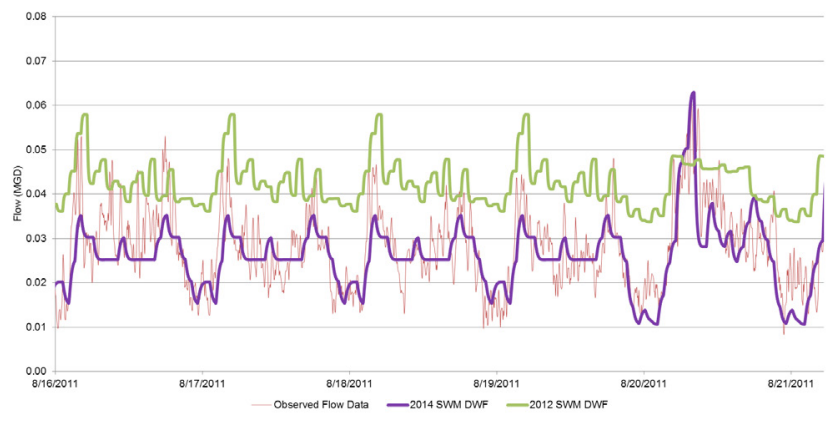

Figure 9 DWF calibration comparison.

\section{Groundwater Response}

A review of the observed data revealed an elevated baseflow from April through June, and then again mid-way through June to August. The period from August through October saw no elevated baseflow. Figure 10 below shows this elevated baseflow behavior indicated by the red line.

The elevated baseflow that exists for several months during an extended wet period of back-to-back storm events is indicative of an extended groundwater infiltration response. To simulate this elevated baseflow, groundwater was added to the SWM through the use of the Aquifer module. The Aquifer module within the SWM provides additional capability to represent the recession of a wet weather infiltration and inflow (I/I) response because of its 
ability to track a simulated groundwater level in response to rain events. This was expected to also provide a better estimate of the total event volume.

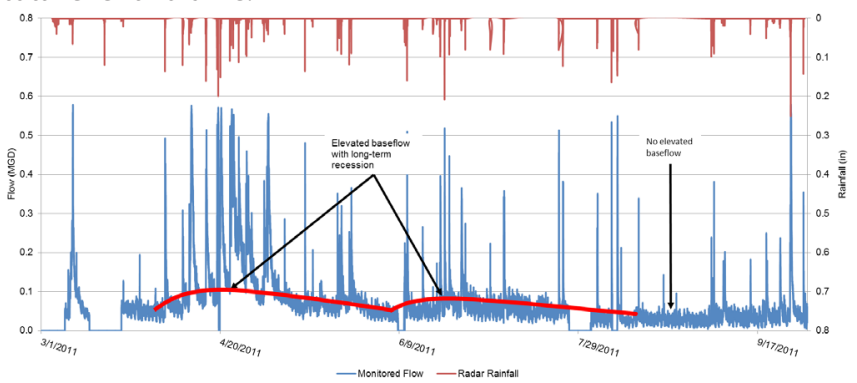

Figure 10 SSO 228 elevated baseflow conditions.

\section{Aquifer Module}

The Aquifer module within the USEPA SWMM5 framework allows for a completely separate flow source from the RDIl generated by the RTK unit hydrographs, which are also used in the SWM, and discussed later. The Aquifer module computes the level of an upper aquifer that is dependent on rainfall. Inflow from the aquifer into the sanitary sewer is dependent on the elevation of the groundwater table. An increased amount of infiltration and inflow can be observed when the groundwater table is higher than a defined invert of a collection system structure. As the collection system receives the groundwater flow, the groundwater table will drain and recede, and flow to the collection system will decrease. The level of the aquifer can also recede due to loss of flow to the lower aquifer.

RDII into the SSO 228 collection system generated by RTK unit hydrographs makes use of a representative sewershed area that is separate from the Aquifer module. Because of this, a representative aquifer subcatchment was created for each inflow node in the SSO 228 system to charge the corresponding aquifer that would also be assigned to each inflow node. As a starting point, the representative subcatchments were based on the same delineation that was developed for the hydrology refinement shown previously in Figure 4. These representative aquifer subcatchment areas were later adjusted to aid in calibrating the aquifer charging, in addition to several other Aquifer module parameters, which are discussed below. During a rain event, the surface runoff from the representative subcatchments discharges out of the SSO 228 system to an arbitrary outfall. The groundwater, however, charges the aquifer assigned to the representative subcatchment. Once the groundwater table in the aquifer rises above the threshold elevation that was established during calibration, infiltration to the collection system occurs. All the aquifers in the SSO 228 area were calibrated using a single set of aquifer parameters. Figure 11 below provides a depiction of how the Aquifer module generates flow in combination with the RTK unit hydrographs in the SWM.

The Aquifer module calibration was used to provide a long term recession inflow after extended periods of wet weather. Calibration of the long term response aquifer requires continuous simulations for the entire monitored period to evaluate its performance when tracking and simulating the rise and fall of the groundwater table.

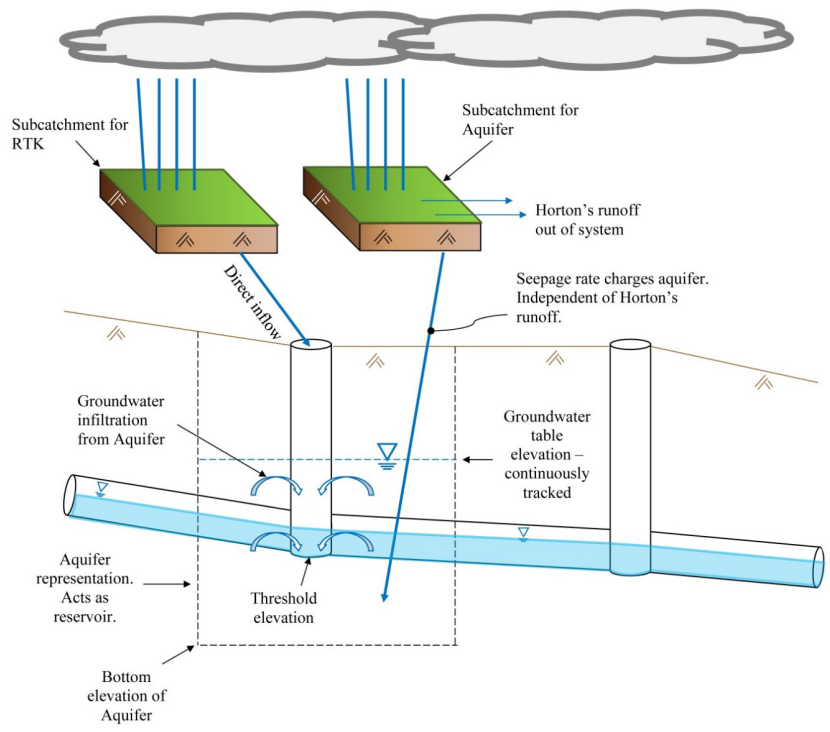

Figure 11 Flow generation.

Four parameters were found to be particularly sensitive in calibrating the aquifer: aquifer area, lower groundwater loss rate, the bottom elevation of the aquifer and the initial water table elevation. Together, these parameters define and track the varying groundwater table elevation. Once the aquifer has been sufficiently charged and rises above what is defined as the threshold elevation, groundwater from the aquifer begins to infiltrate into the collection system.

Figure 12 shows a continuous plot for the entire monitoring period of the observed data compared to the modeled dry weather flow and elevated baseflow resulting from the addition of the Aquifer module. Because the Aquifer module was used to track a rainfall dependent continually varying groundwater level at each inflow node, antecedent moisture conditions were effectively simulated. This is evident by the SWM's ability to elevate the baseflow during wet periods and recede over a long duration. It is also evident during dry conditions, when the baseflow is not elevated.

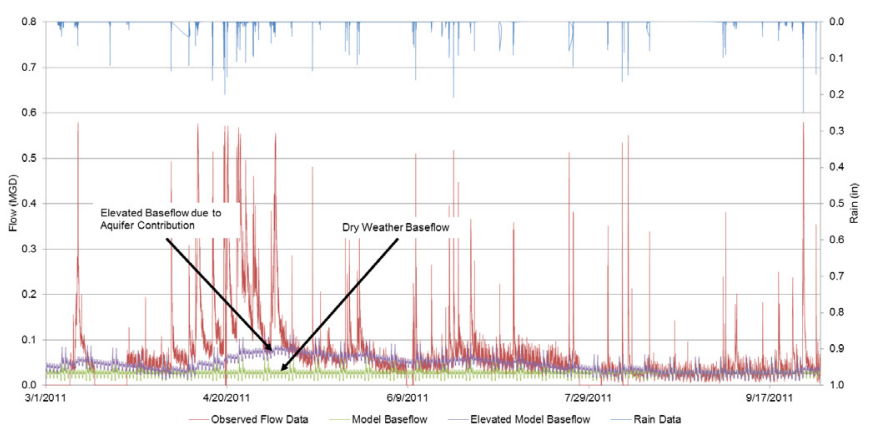

Figure 12 SSO 228 elevated baseflow development. 


\section{RTK Unit Hydrographs}

As was shown in Figure 11, RTK unit hydrographs were also used to generate RDIl, where $R$ represents the rainfall capture coefficient, $T$ represents the time for the RDII hydrograph to peak and $K$ is the ratio of the falling limb duration to the rising limb duration of the RDII hydrograph. The RTK calibration made use of the initial abstraction and drying time parameters in order to simulate antecedent moisture conditions for the short term RDII response. When reviewing the monitoring data for the entire period, a higher response was observed in March and April than was observed for the remainder of the monitoring period. Evidence of this can be seen in Figure 11. As such, seasonal variation was used for the RTK parameters to represent higher capture values and wetter moisture conditions in the spring.

\section{Results and Conclusions}

\subsection{Assessment of the Aquifer Module}

The 2014 model results (shown in Section 7.2) compared well with the observed flow data from the SSO 228 area. Peak flow rates during an event are primarily the result of a short term RDII response. Depending on the antecedent moisture conditions of the soil and characteristics of the watershed, additional flow beyond the short term RDIl response may be observed through either a short or long term groundwater response. The short term groundwater response is more immediate, potentially contributing flow during the event depending on the elevation of the groundwater table within the aquifer, as well as after the event on the recession limb of the overall RDII hydrograph. In general, flow from a long term groundwater response is typically delayed, and therefore is indirectly dependent on rainfall. As such, a long term groundwater response from a wet weather event is typically observed on the recession limb of an RDII response hydrograph, as well as after the wet weather event has occurred. Continued wet weather will elevate the ground water table causing continued contribution to the baseflow from groundwater infiltration.

An example of the long term groundwater response flow behavior was provided in Figure 10. The long term groundwater response from groundwater infiltration may potentially contribute to the peak flow rate depending on the rate at which successive wet weather events occur. However, a long term groundwater contribution during an event typically accounts for only a small portion of the overall peak flows. Also, the long term groundwater contribution is due to the steady buildup of groundwater from multiple events. Therefore, matching observed peak flows is primarily the result of short term RDII response parameters.

Since SSO 228 is a sanitary-only system, RTK parameters were used to represent the short term RDII response. The model can simulate several observed back-to-back peak flow rates, particularly when successive storm events occur within a short interevent duration, using the RTK parameters. However, tracking the antecedent moisture conditions through the use of initial abstraction and drying time allows the model to adjust the short term peak flow response based on the varying moisture content of the soil as each successive storm occurs. As previously discussed, the use of a short term aquifer response to increase the simulated flow during wet weather periods can also assist the model in simulating the observed peak flows. For the SSO 228 area, the addition of a short term aquifer was not needed to meet the MSDGC modeling standards. Table 3 provides a summary of the parameters available for simulating RDII, and specifies which were used for the calibration refinement of SSO 228.

Table 3 Parameters used for 2014 SSO 228 calibration refinement.

\begin{tabular}{lc}
\hline \multicolumn{1}{c}{ Parameter } & Used \\
\hline$R T K^{(1)}$ & Yes \\
Initial Abstraction & Yes \\
Drying Time & Yes \\
Starting Depth & \\
Monthly Variation of RTK & \\
Seasonal Variation of RTK & Yes \\
Short Term Aquifer Module & \\
Long Term Aquifer Module & Yes \\
(1) Short term, medium term and long term response unit hydrographs were all used.
\end{tabular}

Figure 13 shows a comparison of the SSO 228 SWM being run with and without the contribution from the long term Aquifer module for the April 22 to April 30 period, with all other flow components active for both scenarios.

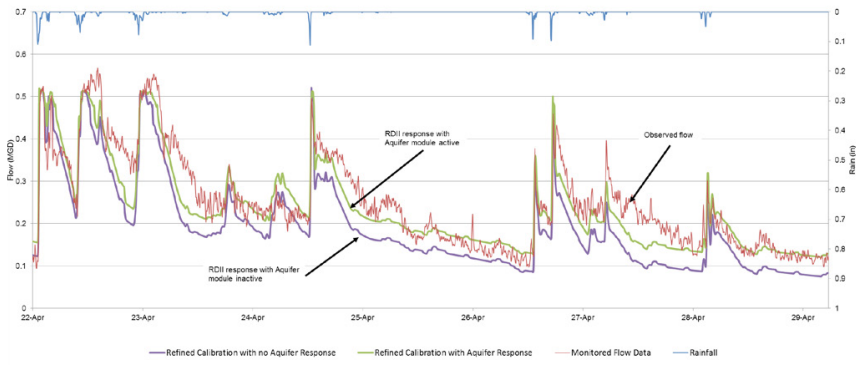

Figure 13 Aquifer contribution comparison for April 22-30.

When the SSO 228 SWM is run without the aquifer, the recession side of the RDII response is under-predicted. Table 4 shows a comparison of the results of the April 22 event for the SWM simulations with and without an active Aquifer module.

Table 42014 calibration aquifer contribution comparison for April 22nd event.

\begin{tabular}{lcccccc}
\hline \multicolumn{1}{c}{$\begin{array}{c}\text { Aquifer } \\
\text { Module }\end{array}$} & \multicolumn{3}{c}{ Peak Flow (MGD) } & \multicolumn{3}{c}{ Volume (MG) } \\
& Modeled & \% Difference & Observed & Modeled & \% Difference \\
\hline Active & 0.57 & 0.52 & $-9 \%$ & 1.83 & 1.73 & $-5 \%$ \\
Inactive & 0.57 & 0.52 & $-9 \%$ & 1.83 & 1.41 & $-23 \%$ \\
\hline
\end{tabular}

To test the overall contribution and assess the added benefit of the Aquifer module, the total volume of underflow generated by the SSO 228 SWM at the metered location downstream of the diversion for the entire continuous simulation period from March through September was calculated. The total simulated 
volumes for the active and inactive Aquifer module models were compared to each other, as well as the 2012 UDAB calibration effort. Table 5 shows the comparison. The volumes presented represent the total volume discharged to the downstream system as measured at the flow monitor location.

Table 5 SSO 228 total volume comparisons for entire monitored period (2011-03 through 2011-09).

\begin{tabular}{lcc}
\hline \multicolumn{1}{c}{ Scenario } & Total Volume (MG) $)^{(1)}$ & \% Difference from Observed \\
\hline Observed Flow & 14.1 & \\
2012 Calibration & 13.0 & $-8 \%$ \\
2014 Calibration Without Aquifer & 10.1 & $-28 \%$ \\
2014 Calibration With Aquifer & 13.7 & $-3 \%$ \\
\hline
\end{tabular}

(1)Periods with velocity 0 in the observed data were omitted from the calculation for all scenarios

\subsection{Calibration and Validation Results}

Table 6 provides a summary of the calibration and validation events for the 2014 calibration-validation effort.

Table 62014 refined calibration and validation results (monitor LM-UDC-001).

\begin{tabular}{lcccccc}
\hline \multirow{2}{*}{ Storm Event } & \multicolumn{3}{c}{ Peak Flow } & \multicolumn{3}{c}{ Total Event Volume (MG) } \\
& Observed & Modeled & \% Difference & Observed & Modeled & \% Difference \\
\hline April 4-6, 2011 & 0.49 & 0.52 & $6 \%$ & 0.20 & 0.23 & $15 \%$ \\
April 11-15, 2011 & 0.58 & 0.50 & $-14 \%$ & 0.71 & 0.71 & $0 \%$ \\
May 26-28, 2011 & 0.36 & 0.39 & $8 \%$ & 0.24 & 0.22 & $-8 \%$ \\
June 10-12, 2011 & 0.51 & 0.50 & $-2 \%$ & 0.15 & 0.17 & $13 \%$ \\
\hline & \multicolumn{7}{c}{ Validation } \\
\hline April 19-22, 2011 & 0.57 & 0.53 & $-7 \%$ & 0.66 & 0.74 & $12 \%$ \\
April 22-30, 2011 & 0.57 & 0.52 & $-9 \%$ & 1.83 & 1.73 & $-5 \%$ \\
July 8-9, 2011 & 0.36 & 0.33 & $-8 \%$ & 0.11 & 0.10 & $-9 \%$ \\
August 8-9, 2011 & 0.55 & 0.52 & $-5 \%$ & 0.09 & 0.14 & $56 \%$ \\
\hline
\end{tabular}

The results demonstrate that the SWM meets MSDGC's most recent modeling standards for all but one validation storm event. The observed versus modeled peak depths compare well, as shown on the flow versus depth scatter plot in Figure 14. Since the modeled flow versus depth relationship aligned with the observed flow versus depth relationship, the depth calibration was assumed to be achieved.

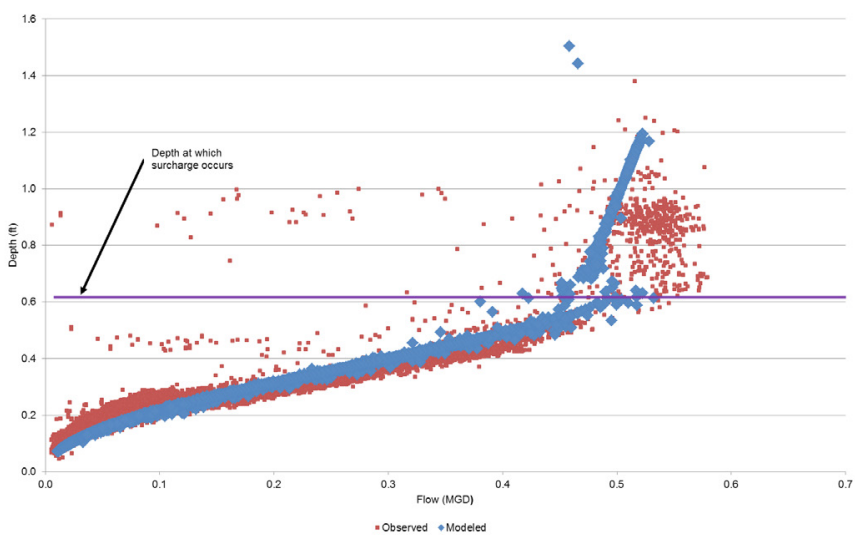

Figure 14 Flow versus depth scatter plot comparison.

\subsection{Calibration Comparison of 2014 and 2012}

Table 7 provides a comparison of the results from the 2012 UDAB calibration to the 2014 refined calibration. This table highlights the overall improvement in the SSO 228 area.

Table 7 Comparison of 2012 and 2014 calibration-validation results (monitor LM-UDC-011).

\begin{tabular}{lcccc}
\hline \multirow{2}{*}{ Storm Event } & \multicolumn{2}{c}{ Peak Flow \% Difference } & \multicolumn{2}{c}{ Total Event Volume \% Difference } \\
& 2012 & 2014 & 2012 & 2014 \\
\hline \multicolumn{5}{c}{ Calibration } \\
\hline April 4-6, 2011 & $16 \%$ & $6 \%$ & $52 \%$ & $15 \%$ \\
April 11-15, 2011 & $-5 \%$ & $-14 \%$ & $-5 \%$ & $0 \%$ \\
May 26-28, 2011 & $-5 \%$ & $8 \%$ & $-4 \%$ & $-8 \%$ \\
June 10-12, 2011 & $16 \%$ & $-2 \%$ & $24 \%$ & $13 \%$ \\
\hline & \multicolumn{5}{c}{ Validation } \\
\hline April 19-22, 2011 & $3 \%$ & $-7 \%$ & $1 \%$ & $12 \%$ \\
April 22-30, 2011 & $3 \%$ & $-9 \%$ & $-19 \%$ & $-5 \%$ \\
July 8-9, 2011 & $33 \%$ & $-8 \%$ & $0 \%$ & $-9 \%$ \\
August 8-9, 2011 & $5 \%$ & $-5 \%$ & $-11 \%$ & $56 \%$ \\
\hline
\end{tabular}

\subsection{Design Storm Evaluation}

The planned improvement for SSO 228 involves constructing a new $15 \mathrm{in}$. $(0.4 \mathrm{~m})$ relief sewer sized for the peak 10 y $24 \mathrm{~h}$ SCS Type II distribution design storm overflow rate. The refined SSO 228 SWM was run for the $10 y$ storm to determine how the refinement would affect the predicted flow rates and required relief sewer sizes. These flows and relief sewer sizes were also compared to the 2012 calibrated SWM peak flows. The results are shown in Table 8.

Table 8 Peak 10 y 24 h SCS Type II SSO 228 overflow rate and required relief sewer size.

\begin{tabular}{lcc}
\hline Calibration effort & 2012 & 2014 \\
Peak Flow (MGD) & 2.1 & 1.5 \\
Required Diameter (in.) & 15 & 12 \\
WWIP Mandated Diameter (in.) & 18 & \\
\hline
\end{tabular}

As shown in Table 8, the 2014 refined calibration resulted in a lower peak overflow rate from SSO 228 for the 10 y $24 \mathrm{~h} \mathrm{SCS}$ Type II distribution design storm. The revised RTK parameters and the varied peak flow rate timing from the smaller subareas were the primary reasons the 2014 refined calibration model simulates an overall lower peak flow rate for the SSO 228 area.

Based on the peak $10 \mathrm{y}$ overflow rates provided by the 2012 SWM, the current design plans for the SSO 228 relief sewer specify a $15 \mathrm{in}$. $(0.4 \mathrm{~m})$ pipe to convey the $10 \mathrm{y}$ flow. Based on the 2014 SWM calibration refinement, a 12 in. $(0.3 \mathrm{~m})$ pipe would provide adequate relief capacity for conveyance of overflow from SSO 228. However, the Environmental Protection Agency is requiring an $18 \mathrm{in}$. (0.45 $\mathrm{m}$ ) pipe, in either case, to meet the requirements as stated in the WWIP (Metropolitan Sewer District of Greater Cincinnati 2009). 


\section{Model Complexity Guidelines}

The goal of any calibration should always be to use the simplest means possible to achieve a properly validated model that is sufficient for its intended purpose. With the vast variability of each watershed's climate and topography and age of the collection system, no industry standard exists for defining exactly what parameters need to be used for a particular type of system. Because of the multitude of variables that can influence a model's simulated flow response, and the oftentimes subjective nature of evaluating the adequacy of a model's performance, determining the proper approach to calibration is typically an iterative process.

Prior to performing a calibration, the modeling team must consider what parameters will likely be needed to achieve the proper validation based on the observed flow behavior. To assist in future modeling efforts, a flowchart was developed to aid in the process of determining which modeling techniques may be needed. Figure 15 can be used as guidance when reviewing flow monitor data prior to beginning a calibration effort.

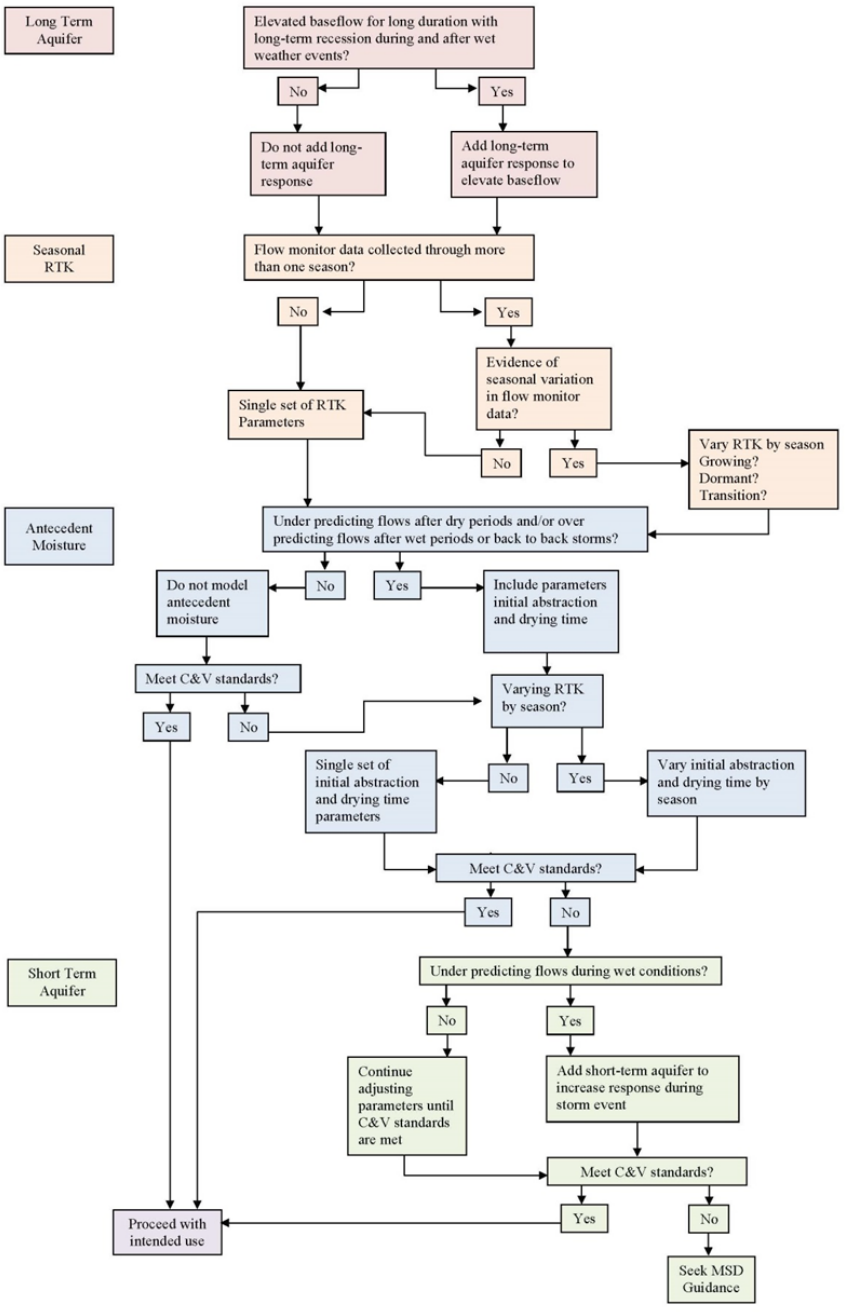

Figure 15 Parameter selection guidance for modeling of sanitary systems.
Using this guidance in addition to considering the model's intended purpose, as well as considering budget and schedule constraints, can lead to ensuring that the model achieves validation while keeping the model representation as simple as possible.

\section{Findings and Recommendations}

The SSO 228 SWM representation of the hydrology and hydraulics was updated and further calibrated to meet the requirements of the February 2013 MSDGC Modeling Guidelines and Standards: Volume I-System Wide Model, Rev. 3 (XCG Consultants 2013). The hydraulic representation was updated to include additional upstream pipes within the SSO 228 collection system and the tributary sewershed areas were further subdivided, redelineated and redistributed. The flow generation parameters within the SWM were updated to include seasonally varied RTK parameters, an initial abstraction value, drying time and a groundwater response via the Aquifer module. These additional parameters improved the model's ability to simulate antecedent moisture conditions. As such, the SSO 228 SWM was able to meet the current MSDGC modeling standards. The revised 2014 model results in a reduction of approximately $30 \%$ in the predicted peak 10 y $24 \mathrm{~h}$ SCS Type II distribution design flow when compared to the 2012 model.

\section{References}

City of Cincinnati. 2012. Cincinnati Area Geographic Information System. Cincinnati, $\mathrm{OH}$ : City of Cincinnati. http://cagismaps.hamilton-co.org/cagisportal.

Metropolitan Sewer District of Greater Cincinnati. 2009. Final Wet Weather Improvement Program. Washington, DC: USEPA. https://archive.epa.gov/r5water/lowermillcreek/web/pdf/ final_wwip.pdf.

Vieux, Inc. 2011. Radar Rainfall Analysis, May 2011 Summary Report. Cincinnati, OH: Metropolitan Sewer District of Greater Cincinnati.

Wade Trim Ohio, Inc. 2012. Task 207 Revised Model Validation Technical Memorandum. Cincinnati, $\mathrm{OH}$ : Metropolitan Sewer District of Greater Cincinnati.

Wade Trim Ohio, Inc. 2013. Business Case Evaluation. Cincinnati, $\mathrm{OH}$ : Metropolitan Sewer District of Greater Cincinnati.

Wastewater Planning Users Group (WaPUG). 2002. Code of Practice for the Hydraulic Modelling of Sewer Systems, 3rd ed. UK: Wastewater Planning Users Group. http://www.ciwem.org/wp-content/uploads/2016/05/Codeof-Practice-for-the-Hydraulic-Modelling-of-Sewer-Systems.pdf

XCG Consultants, Inc. 2012. MSDGC Modeling Guidelines and Standards: Volume I-System Wide Model, Rev. 1. Cincinnati, OH: Metropolitan Sewer District of Greater Cincinnati.

XCG Consultants, Inc. 2013. MSDGC Modeling Guidelines and Standards: Volume I-System Wide Model, Rev. 3. Cincinnati, OH: Metropolitan Sewer District of Greater Cincinnati. https://www.msdgc.org/downloads/customer_care/forms_and_ documents/modeling/modeling_guidelines_and_standards.pdf. 